\title{
Five year review of open radical nephrectomies at a regional hospital in South Africa: room for improvement
}

\author{
A Singh, ${ }^{1,2}$ RJ Urry, ${ }^{1,2}$ TC Hardcastle ${ }^{2,3,4}$ \\ ${ }^{1}$ Department of Urology, Greys Hospital \\ ${ }^{2}$ Nelson R. Mandela School of Medicine, University of KwaZulu-Natal \\ ${ }^{3}$ Trauma Surgery Training Unit, Department of Surgery, University of KwaZulu-Natal \\ ${ }^{4}$ Trauma Service, Inkosi Albert Luthuli Central Hospital
}

Corresponding author: Avikar Singh (avikarsingh@gmail.com)

\begin{abstract}
Background: To review the presentation and outcomes of patients undergoing open radical nephrectomy (ORN) for renal cell carcinoma (RCC) at a regional hospital in KwaZulu-Natal, South Africa.

Methods: A retrospective chart review was performed of patients having undergone nephrectomy at St Aidan's hospital between 2010 and 2015, focusing on those with RCC. Demographic, operative, histopathology and outcomes data were collected.

Results: Fifty-two patients (51\%) had ORN for suspected malignant disease. Forty-one RCCs were found including one incidental finding at simple nephrectomy. Data was insufficient to assess risk factors for RCC. HIV positive patients tended to present earlier (45 vs. 53 years). The mean tumour size was $10 \mathrm{~cm}$ and organ confined disease was present in $73.2 \%$ of patients. Only 11 patients $(26.8 \%)$ had pT1 disease. The high-grade complication rate was $9.8 \%$, in-hospital mortality rate $4.9 \%$ and transfusion rate $51.2 \%$. The median operating time was $1 \mathrm{~h} 50 \mathrm{~min}$ and length of hospital stay 13 days.

Conclusions: Open radical nephrectomy is the standard surgical treatment for RCC at regional level in South Africa. Patients tend to present at a younger age, particularly if HIV positive, and with large tumours. Further research into risk factors for $\mathrm{RCC}$ in the South African population is needed. There are high complication and transfusion rates in patients undergoing ORN. Review of accessibility of blood at St Aidan's hospital and revision of the transfusion protocol is suggested. A followup study to assess the feasibility and cost-effectiveness of laparoscopic nephrectomy in the resource-constrained South African environment is necessary.

Keywords: Renal cell carcinoma, nephrectomy, open nephrectomy, radical nephrectomy, transfusion rate, complications, South Africa
\end{abstract}

S Afr J Surg 2018;56(1)

http://dx.doi.org/10.17159/2078-5151/2018/v56n1a2195

\section{Introduction}

There is a paucity of published local data describing indications for and outcomes of nephrectomy in South Africa. It appears that patients with renal cell carcinoma (RCC) in KwaZulu-Natal (KZN) present at a young age with advanced disease. Furthermore, there is concern that there is a high complication rate in patients undergoing open radical nephrectomy (ORN). A better understanding of presentation and outcomes in these patients is necessary in the era of laparoscopic nephrectomy and this study attempts to provide this in the context of a resource constrained environment.

\section{Setting}

St Aidan's hospital in Durban, South Africa, provides regional level urology care to approximately 3.4 million people. ${ }^{1}$ Most elective nephrectomies for the large eThekwini district are performed at St Aidan's hospital, excluding high-risk patients who are referred to a tertiary facility. ${ }^{2}$

\section{Methods}

\section{Data collection}

A retrospective chart review of patients having undergone nephrectomy at St Aidan's hospital between 31 December 2010 and 31 December 2015 was performed, focusing on those patients with RCC. Data collected included demographic information, preoperative imaging findings, operative information (surgical approach, operative time, estimated blood loss, and transfusion requirements) and postoperative outcomes (histopathology findings, length of hospital stay 
and complications). Malignancies were staged according to the American Joint Committee on Cancer TNM classification and complications were categorized according to the ClavienDindo classification. ${ }^{3,4}$ This study was approved by the Bioethics Research Ethics Committee of the University of KZN (BE258/16).

\section{Statistical analysis}

IBM Statistical Package for Social Sciences (SPSS) (IBM Corp, Armonk, NY) was used for statistical analysis. Descriptive statistics (mean and standard deviation or median and interquartile ranges) were calculated. The Pearson Chisquared test $\left(\chi^{2}\right)$ was used to compare categorical variables. If an expected cell count was less than five observations, the Fischer's Exact test was used. The two-sample Wilcoxon ranksum (Mann-Whitney) test was used to compare the variables with non-parametric distributions, across subgroups. Multiple univariate logistic regressions were performed to determine the odds ratio for risk factors. Following identification of risk factors, a multivariate regression was performed to confirm significance of independent risk factors. A p-value of less than $0.05(5 \%)$ was considered statistically significant. With the known population of the area served by St Aidan's hospital, Globocan data was used to calculate the expected incidence of RCC. ${ }^{5}$

\section{Results}

\section{Surgical approach}

Fifty-two patients (51\%) underwent ORN and 50 (49\%) underwent simple nephrectomy for benign disease. Open nephrectomy was performed in all cases and no laparoscopic nephrectomies or partial nephrectomies were performed.

\section{Histopathological findings}

Of the ORNs, 48 were for suspected RCC and 4 were for suspected upper tract transitional cell carcinoma (TCC). The distribution of histopathological findings is illustrated in Figure 1.

At histopathology, 40 patients (77\%) who underwent ORN were found to have RCC and $5(9 \%)$ were found to have TCC. Four benign renal tumours were found, made up of oncocytoma $(n=2)$, cystic nephroma $(n=1)$ and angiomyolipoma $(n=1)$. XGP was mistaken for RCC in 2 patients. One patient who had a simple nephrectomy was incidentally found to have RCC.

\section{Renal Cell Carcinoma}

\section{Patient Characteristics}

The median age of patients with RCC was 53 years. Sixtythree percent $(n=26)$ were male and $37 \%(n=15)$ were female. The majority were Black $(61 \%, \mathrm{n}=25)$, followed by Indian $(27 \%, n=11)$, White $(7 \%, n=3)$ and mixed race $(5 \%, n=2)$. The mean body weight was $71.1 \mathrm{~kg}$ (range $45-103 \mathrm{~kg}$ ). Fortyfour percent of patients were smokers $(n=18), 17 \%$ were HIV-positive $(n=7), 15 \%$ had diabetes mellitus (DM) $(n=6)$ and $36 \%$ were hypertensive $(n=15)$. We expect an incidence of kidney cancer of 1.2 per 100000 people per year, which equates to 40.8 cases per year or more than 200 cases over the 5-year period.

\section{Tumour Characteristics}

The tumour characteristics for the patients with RCC are described in Table 1.

Organ confined disease (T1-T2, N0, M0) was present in 30 patients $(73.2 \%)$. However, only 11 patients $(26.8 \%)$ had pT1 disease. There was a significant association between the pathological $\mathrm{T}$ stage and the presence of positive surgical margins (PSM) $(p=0.005)$, but not between pathological

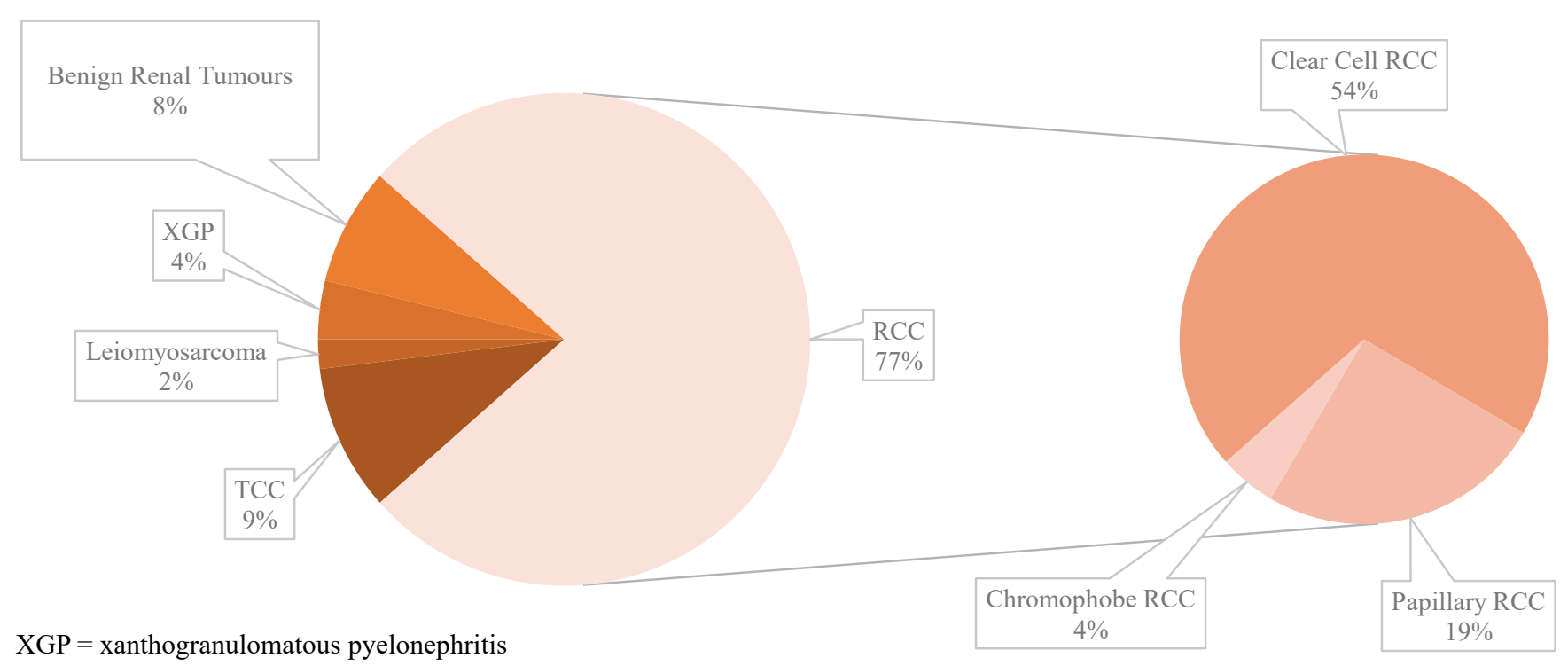

Figure 1: Distribution of histopathological findings in patients undergoing ORN 


\section{Table 1: Tumour characteristics of RCCs $(n=41)$}

\begin{tabular}{|c|c|c|}
\hline & $\mathbf{n}$ & $(\%)$ \\
\hline \multicolumn{3}{|l|}{ Pathological T Stage } \\
\hline $\mathrm{Tx}$ & 0 & $(0.0)$ \\
\hline T1a & 4 & $(9.8)$ \\
\hline $\mathrm{T} 1 \mathrm{~b}$ & 7 & $(17.1)$ \\
\hline $\mathrm{T} 2 \mathrm{a}$ & 11 & $(26.8)$ \\
\hline $\mathrm{T} 2 \mathrm{~b}$ & 14 & $(34.1)$ \\
\hline $\mathrm{T} 3 \mathrm{a}$ & 4 & $(9.8)$ \\
\hline $\mathrm{T} 3 \mathrm{~b}$ & 0 & $(0.0)$ \\
\hline $\mathrm{T} 3 \mathrm{c}$ & 0 & $(0.0)$ \\
\hline $\mathrm{T} 4$ & 1 & $(2.4)$ \\
\hline \multicolumn{3}{|l|}{ N Stage } \\
\hline No & 33 & $(80.5)$ \\
\hline N1 & 6 & $(14.6)$ \\
\hline $\mathrm{Nx}$ & 2 & $(4.9)$ \\
\hline \multicolumn{3}{|l|}{ M Stage } \\
\hline M0 & 37 & $(90.2)$ \\
\hline M1 & 4 & $(9.8)$ \\
\hline \multicolumn{3}{|l|}{ Fuhrman Grade for RCC } \\
\hline Grade 1 & 4 & $(9.8)$ \\
\hline Grade 2 & 16 & $(39.0)$ \\
\hline Grade 3 & 17 & $(41.5)$ \\
\hline Grade 4 & 4 & $(9.8)$ \\
\hline \multicolumn{3}{|l|}{ Surgical Margin } \\
\hline Negative Margin & 37 & $(90.2)$ \\
\hline Positive Margin & 4 & $(9.8)$ \\
\hline
\end{tabular}

$\mathrm{T}$ stage and positive $\mathrm{N}$ or $\mathrm{M}$ stage. There was no association between Fuhrman grade and presence of PSM, positive $\mathrm{N}$ stage or positive $\mathrm{M}$ stage. The median tumour size measured on computed tomography (CT) scan was $8.15 \mathrm{~cm}$ (range 2-22 cm) compared to $10 \mathrm{~cm}$ (range $1-21 \mathrm{~cm}$ ) measured at histopathology assessment. There was no significant difference between measurement on $\mathrm{CT}$ and at histopathology assessment $(\mathrm{p}=0.055)$.

\section{Risk Factors}

Smoking (OR3.2, 95\% CI 1.3-7.7, $\mathrm{p}=0.01$ ) was identified as a risk factor for RCC on univariate analysis, but was not significant on multivariate analysis. Male gender tended towards increased risk, but was not significant (OR2.2, CI 1.0-4.9, $\mathrm{p}=0.06$ ). Race, age, HIV status, DM and hypertension were not found to be risk factors. There was insufficient data to assess obesity as a risk factor. HIV positive patients tended to present at a younger age than other patients
(45 vs. 53 years) but this difference was not significant $(\mathrm{p}=0.063)$. There was no difference in Fuhrman grade, T-stage, $\mathrm{N}$-stage and M-stage between HIV positive and HIV negative patients.

\section{Outcomes}

The mean starting haemoglobin $(\mathrm{Hb})$ level was $12 \mathrm{~g} / \mathrm{dl}$ (range $7.2-16.6 \mathrm{~g} / \mathrm{dl}$ ). The mean estimated blood loss was $276 \mathrm{ml}$ (range 50-2000 ml). The transfusion rate was $51.2 \%$ with a mean of 2.4 units transfused per patient receiving transfusion. There was a significant association between blood loss and number of units transfused $(p<0.001)$ but not between starting $\mathrm{Hb}$ and number of units transfused. Blood transfusion was given in 15 patients whose blood loss was $300 \mathrm{ml}$ or less. The mean starting $\mathrm{Hb}$ in these patients was $11.2 \mathrm{~g} / \mathrm{dl}$ (range $8.2-14.4 \mathrm{~g} / \mathrm{dl}$ ) with no association between starting $\mathrm{Hb}$ and units transfused. The median operating time was $1 \mathrm{~h} 50 \mathrm{~min}$ (range $54 \mathrm{~min}-6 \mathrm{~h} 00 \mathrm{~min}$ ). The median length of hospital stay was 13 days (range 3 to 40 days). Surgical complications are described in Table 2.

\section{Table 2: Complications after ORN}

\begin{tabular}{lcc}
\hline & $\mathbf{n}$ & $\mathbf{( \% )}$ \\
\hline Low grade (Clavien-Dindo grade I-II) & 37 & $(90.2)$ \\
\hline $\begin{array}{l}\text { Transfusion } \\
\text { Prolonged analgesic, antipyretic or } \\
\text { physiotherapy requirement }\end{array}$ & 22 & $(51.2)$ \\
$\quad \begin{array}{l}\text { Post-operative infection requiring } \\
\text { antibiotics }\end{array}$ & 18 & $(43.9)$ \\
High grade (Clavien-Dindo grade III-V) & 4 & $(26.8)$ \\
\hline $\begin{array}{l}\text { Death } \\
\text { IVC thrombosis requiring anti- }\end{array}$ & 2 & $(4.9)$ \\
$\quad \begin{array}{l}\text { coagulation } \\
\text { Intra-operative pancreatic injury } \\
\text { managed conservatively }\end{array}$ & 1 & $(2.4)$ \\
\hline
\end{tabular}

There were serious complications (Clavien-Dindo III-V) in four patients $(9.8 \%)$. One patient died in the intensive care unit (ICU) with multiorgan failure following an inferior vena cava (IVC) injury with $2000 \mathrm{ml}$ intraoperative blood loss. Another patient died in hospital having deteriorated after a cytoreductive nephrectomy in the presence of metastatic disease.

\section{Discussion}

In South Africa, particularly in the resource constrained state sector, there is a poor culture of audit and review. Practices and protocols which may not be evidence based are followed, sometimes resulting in wasting of resources or potential harm to patients. This paper illustrates the importance of using evidence-based protocols and of reviewing outcomes with the goal of improving quality of care. 
The practice at St Aidan's hospital is to perform ORN. The reason for this is the lack of laparoscopic facilities and laparoscopically trained surgeons at the hospital. Laparoscopic nephrectomy was first described in $1991,{ }^{6}$ is currently considered the gold standard for radical nephrectomy, ${ }^{7}$ and is being performed at other state hospitals in $\mathrm{KZN}^{8}$ It is well established that laparoscopic nephrectomy offers equivalent oncological outcomes and improved postoperative outcomes compared to open nephrectomy. ${ }^{7,9}$ Further research into the feasibility and cost-effectiveness of laparoscopic surgery in our resource-constrained environment is required. Additionally, the investment in laparoscopic equipment and training of surgeons in laparoscopic surgery in KZN is a necessary first step to bridge the gap between the current practice and the gold standard.

A study from the UK of outcomes after nephrectomy described a Clavien-Dindo high grade (grade III or greater) complication rate of $3.9 \% .{ }^{10}$ Most complications were seen after partial nephrectomy, and most cases were performed by minimally invasive approaches. There was an overall 30 -day mortality of $0.55 \%$ and a transfusion rate of $8.4 \%$. The findings in this study of high-grade complication rate of $9.8 \%$, in-hospital mortality rate of $4.9 \%$ and transfusion rate of $51.2 \%$ indicate that there is a lot of room for improvement. The length of hospital stay in this study was longer than in a local study describing laparoscopic nephrectomy ${ }^{8}$ and in international studies. ${ }^{10}$ This is due to open surgery being used over less invasive techniques, higher morbidity rates and logistical factors which prevent patients from being discharged.

The high blood transfusion rate in this study warrants further discussion. There is evidence that perioperative blood transfusion is associated with increased morbidity and mortality after radical nephrectomy, ${ }^{11}$ and that a restrictive transfusion strategy is preferred. One of the factors driving the transfusion rate in this study is the absence of an on-site blood bank. The decision to order blood may be influenced by the short-term concern about need for rapid access to blood if required, without consideration of the implications in terms of cost to the hospital and blood availability for other patients. The threshold for transfusion is lower if blood has been ordered and delivered. Such a transfusion protocol does not appear to be evidence-based. Review of accessibility of blood at St Aidan's hospital and revision of the transfusion protocol is suggested.

We appear to be seeing fewer cases of RCC than expected. Fifty-one RCCs were operated over a 5-year period when over 200 cases were expected for the same period based on incidence and population data. The low number seen in this study can be partly explained by some patients with metastatic disease not being candidates for surgery and some patients being operated at a tertiary referral centre. However, the impression is that there may be a large group of patients not being diagnosed or referred for surgery.

The median age of 53 years in this study is lower than in the literature. ${ }^{7}$ Known risk factors for RCC are hypertension, obesity and male gender. ${ }^{7,12}$ There was not sufficient data to adequately assess risk factors in this study, and further research into risk factors for RCC in a South African population is necessary. The presence of HIV infection suggested a trend towards an earlier age of presentation. The mean age of HIVpositive patients with RCC was lower at 45 years; a finding has already been described in a case series of 9 HIVpositive men with RCC who had a median age of 48 years on presentation. ${ }^{13}$

In this study, tumours were large, with a median diameter of $10 \mathrm{~cm}$ and size was accurately assessed on CT scan. This is larger than in the UK where the median size was $7 \mathrm{~cm}$ for tumours treated with radical nephrectomy and $3 \mathrm{~cm}$ for those treated with partial nephrectomy. ${ }^{10}$ Presentation with larger tumours can be explained by delay in presentation resulting from limited access to healthcare and lower likelihood of cross sectional imaging of the abdomen being performed. Based on tumour size and location, most patients in this study would not have been candidates for nephron sparing surgery and the benefits thereof.

There were some cases in which the preoperative diagnosis was incorrect. Both upper tract TCC and XGP were diagnosed as RCC on preoperative imaging. This is not unexpected, given that both present with renal masses and there is overlap of imaging findings between these lesions and RCC. Four benign tumours were diagnosed as RCC. Once again, this is not unexpected since imaging is not able to differentiate between benign and malignant lesions in all cases, and biopsy of renal masses is not routinely practiced. ${ }^{14}$ In one case, a RCC was found incidentally after simple nephrectomy for a nonfunctioning kidney. This was a small lesion which appears to have been missed on preoperative imaging.

\section{Conclusion}

Open radical nephrectomy is still the standard surgical treatment for RCC at a regional hospital in South Africa. In this setting, patients tend to present at a younger age, particularly if HIVpositive, and with large tumours which are not amenable to partial nephrectomy. The current data is inadequate to assess risk factors for RCC and further research in the South African population is needed. There are high complication and transfusion rates in patients undergoing ORN. The results of this study highlight the importance of following evidence-based protocols and auditing outcomes. Review of accessibility of blood at St Aidan's hospital and revision of the transfusion protocol are suggested. A followup study to assess the feasibility and cost-effectiveness of laparoscopic nephrectomy in the resource-constrained South African environment is necessary.

\section{Conflict of interests}

The authors declare no conflicts of interest. 


\section{Acknowledgements}

The authors would like to thank Dr EHA Goad for his assistance in the design of this study, and Ms Cathy Connoly, specialist biostatistician at the University of KwaZulu-Natal, for her assistance in data analysis.

\section{REFERENCES}

1. Statistics South Africa. Census 2011 Census in brief. [Online]: Statistics South Africa; 2012 [Accessed 24 July 2016]. Available from: www.statssa.gov.za/census/census 2011/ census.../Census_2011_Census_in_brief.pdf

2. KZN Department of Health. Saint Aidans Hospital Page. [Online]. [Accessed 1 August 2016] Available from: http:// www.kznhealth.gov.za/staidanshospital.htm

3. Edge S, Byrd D, Compton C, Fritz A, et al. AJCC Cancer Staging Manual. 7th ed. New York: Springer-Verlag; 2010.

4. Dindo D, Demartines N, Clavien PA. Classification of Surgical Complications: A New Proposal With Evaluation in a Cohort of 6336 Patients and Results of a Survey. Ann Surg. Aug 2004;240(2):205-13. PMID: 15273542.

5. Ferlay J, Soerjomataram I, Ervik M, Dikshit R, et al. Cancer Incidence and Mortality Worldwide: IARC CancerBase No. 11. [Online]. 2013 [Accessed 22 September 2016]. Available from: http://globocan.iarc.fr.

6. Clayman RV , Kavoussi LR , Soper NJ. Laparoscopic nephrectomy. N Engl J Med. 199;324:1370-2. Availble from: https://dx.doi.org/10.1056/NEJM199105093241917. PMID 1826761.

7. European Association of Urology. EAU Guidelines on Renal Cell Carcinoma. March 2016 [Accessed 15 June 2016]. Available from: http://uroweb.org/guideline/renal-cell- carcinoma

8. Conradie MC, Urry RJ, Naidoo D, et al. Advantages of En Bloc Hilar Ligation During Laparoscopic Extirpative Renal Surgery. J Endourol. September 2009;23(9):1503-7. Available from: https://dx.doi.org/10.1089/end.2009.0380. PMID: 19673656.

9. Kercher KW, Heniford BT, Matthews BD, et al. Laparoscopic vs open nephrectomy in 210 consecutive patients. J Endosc Surg. 13 Feb 2003;17:1889-95. Available from: https://dx.doi. org/10.1007/s00464-003-8808-3. PMID: 14569452.

10. Henderson JM, Fowler S, Joyce A, et al. Perioperative outcomes of 6042 nephrectomies in 2012: surgeon-reported results in the UK from the British Association of Urological Surgeons (BAUS) nephrectomy database. BJU Int. 2014;115:121-6. Available from: https://dx.doi.org/10.1111/bju.12770. PMID: 24725810.

11. Sui W, Onyeji I, Matulay J, et al. Perioperative blood transfusion predicts short term morbidity after nephrectomy. Can J Urol. Aug 2016;23(4):8348-55. PMID: 27544557.

12. Zeegers MP, Tan FE, Dorant E, Van den Brandt PA. The impact of characteristics of cigarette smoking on urinary tract cancer risk: a meta-analysis of epidemiologic studies. Cancer. Aug 2000;89(3).

13. Gaughan EM, Dezube BJ, Aboulafia D, et al. Human Immunodeficiency Virus-Associated Renal Cell Carcinoma: A Transatlantic Case Series. Clinical Genitourinary Cancer. Sep 2008;6(2):86-90. Available from: https://https://doi. org/10.3816/CGC.2008.n.013. PMID: 18824430.

14. Kutikov A, Fosset L, Ramachandi P, Tomaszewski JE, Siegelman ES, Banner MP, et al. Incidence of benign pathologic findings at partial nephrectomy for solitary renal mass presumed to be renal cell carcinoma on preoperative imaging. Urology. Oct 2006;68(4):737-40. 